Tijdschr Urol (2021) 11:1

https://doi.org/10.1007/s13629-020-00316-5

Q

Check for
updates

\section{Een gemiste kans?}

Henk G. van der Poel

(C) The Author(s) 2020

$\mathrm{Nu}$ we een doorstart maken met de registraties van blaas-, nier- en prostaatkankerbehandeling is het goed om te kijken naar wat er in Nederland op het gebied van registraties in de gezondheidszorg verder nog gebeurt.

Al 10 jaar geleden zijn er gesprekken geweest tussen de NVU en de DICA-registratie (Dutch Institute for Clinical Auditing). Daar waar de NVU besloot een eigen koers te varen, heeft DICA zich ontwikkeld tot een landelijke registratie voor 22 kwaliteitsregistraties, waarin 1,4 miljoen patiënten inmiddels zijn geregistreerd. Kracht van de organisatie is de directe interpretatie van de uitkomsten en een veel gebruikt auditsysteem. Een aantal wapenfeiten van de DICA-registratie: borstkanker, meer borstcontoursparende ingrepen (van 63 naar 75\%); darmkanker, een daling van de postoperatieve sterfte, complicaties en kosten. In driekwart van de gevallen paste de chirurg zijn procedures aan op basis van vergelijkingen uit de registratie.

Kortom, registreren werkt met name als die wordt gedaan in nauwe samenspraak met het veld en de gegevens op een verstandige manier worden teruggekoppeld. Misschien nog eens praten met DICA?

Open Access This article is distributed under the terms of the Creative Commons Attribution 4.0 International License (http://creativecommons.org/licenses/by/4.0/), which permits unrestricted use, distribution, and reproduction in any medium, provided you give appropriate credit to the original author(s) and the source, provide a link to the Creative Commons license, and indicate if changes were made.

dr. Henk G. van der Poel, hoofdredacteur dr. H. G. van der Poel (凶)

Tijdschrift voor Urologie, Bohn Stafleu van Loghum, Houten, Nederland

h.vd.poel@nki.nl 